\title{
Comparison of efficacy of PGE2 gel, Oral misoprostol and combination of foleys bulb with Oral misoprostol in predicting the Outcome of induction of labour: A randomized controlled trial
}

\author{
Vasanthi Balamurugan $^{1 *}$, Kurian Joseph ${ }^{2}$, Rekha Kurian ${ }^{3}$, Tarun Joseph ${ }^{4}$, Sivashannkari $^{5}$ \\ ${ }^{1}$ Senior resident, ${ }^{2,3}$ Senior Consultant, ${ }^{4,5}$ Consultant, Joseph nursing home, Chennai, Tamil Nadu, India \\ *Corresponding Author: Vasanthi Balamurugan \\ Email: vasanthivaradhan@yahoo.co.in
}

Received: $15^{\text {th }}$ October, 2018

Accepted: $2^{\text {ed }}$ April, 2019

\begin{abstract}
Aim: To compare the efficacy of PGE2 gel (Prostaglandin E2 gel), oral misoprostol and combination group (Foleys bulb + oral misoprostol) in predicting the outcome of induction of labour.

Materials and Methods: This prospective randomized controlled trial included 201 women requiring induction of labour. A total of 67 women were randomly allocated to PGE2 gel group, 69 women to oral misoprostol group, 65 women allocated to the combination group using computer generated allocation sequence. The primary outcomes which was analyzed in the study were time interval between induction and active phase of labour and time interval between induction and delivery.

Results: The mean time interval between induction and active phase of labour was shorter with the combination group when compared with PGE2 gel group \& oral misoprostol group ( $9 \mathrm{hrs}$ vs $16 \mathrm{hrs}$ vs $18 \mathrm{hrs}$, p value 0.002 ). The combination group also resulted in shorter time interval between induction and delivery (16hrs vs $21 \mathrm{hrs}$ vs $25 \mathrm{hrs}$, p value 0.014 ). Highest proportion of women achieved vaginal delivery within $24 \mathrm{hrs}$ from induction in the combination group ( $87 \%$ vs $71 \%$ vs $59 \%$, p value 0.048 ). No significant difference were seen with maternal and neonatal outcomes.

Conclusion: In our study, the combination group achieved shorter time interval between induction and active phase of labour, induction and delivery and higher proportion of vaginal deliveries within $24 \mathrm{hrs}$ from induction when compared to PGE2 gel and oral misoprostol without increasing labor complications.
\end{abstract}

Keywords: Efficacy, Induction of labour, PGE2 gel, Misoprostol, Foleys bulb.

\section{Introduction}

"Induction of labor is the process or treatment that stimulates childbirth and delivery by artificial initiation of labor, before the onset of spontaneous labour.," "The common clinical indication for induction of labor are postterm pregnancy, gestational diabetes, and pregnancy induced hypertensive disorders. 3 ", "Bishop score, has been shown to be an important determinant of outcome of induction." "There are two categories of artificial means of cervical ripening prior to labor induction: mechanical (the foleys bulb and laminaria tents) and pharmacological (prostaglandins PGE1, PGE2). Mechanical devices dilate the cervix by accessing the fetal membrane, and pharmacological preparations cause connective tissue softening, cervical effacement, and uterine activity.,

"Intracervical instillation of PGE2 gel is more effective for induction of labour as it can have a combined effect of cervical ripening and inducing contraction." Local application of PGE2 gel produces connective tissue softening, cervical effacement \& uterine activity." "PGE2 gel can be used successfully in inducing contractions in cases of medical disorders of pregnancy. ${ }^{10,}$

Two low cost cervical ripening methods- low dose oral misoprostol and Foleys bulb are being used in low resource settings. Misoprostol, orally active and heat stable prostaglandin E1 analogue is used for labour induction since 20 years. "A Cochrane review included all studies that used misoprostol for labour induction and concluded that oral regimens are preferred over vaginal regimens as the risk of ascending infection and hyperstimulation is high with

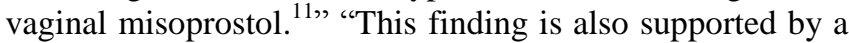
network meta analysis of many studies which used various methods of induction using prostaglandins. ${ }^{12,}$

The two methods - Foleys bulb and low dose oral misoprostol are the optimal choices for low resource settings. "A multicentre Dutch study compared Foleys balloon catheter induction with oral misoprostol and found no differences between groups in any of the major outcomes. ${ }^{13 \text { ", }}$

There is no consensus on the best method of induction. Many combinations methods for induction of labour have been studied till date. This is the first randomised controlled study to assess the efficacy of three different agents for induction of labour.

"The purpose of our study was to compare the efficacy of PGE2 gel, oral misoprostol and combination of Foleys bulb with oral misoprostol to predict the outcome of induction of labour."

\section{Materials and Methods}

The present study was a randomized controlled trial carried out in the department of Obstetrics \& gynaecology, Joseph nursing home, Chennai, from March 2017 to August 2017 after obtaining approval from the Institutional Ethical committee. Informed consent was taken from all cases included in the study. Total of 201 cases were taken in the 
study which was divided into 3 groups by computer generated randomization.

\section{Inclusion Criteria}

Gestational age after 37weeks irrespective of parity

Singleton, cephalic presentation

Intact membranes

Unfavourable cervix (Bishops score <6)

Reassuring cardiotocography

\section{Exclusion Criteria}

Fetal malpresentation

Rupture of membranes

Multifetal gestation

Non reassuring fetal heart rate changes

Fetal growth restriction (defined as estimated fetal weight less than $10^{\text {th }}$ percentile for gestational age)

Fetal demise

Previous cesarean delivery or other uterine surgery (myomectomy, cornual wedge resection)

Anomalous fetus

\section{Primary outcomes}

Time interval between induction and active phase of labour Time interval between induction and delivery.

Patients who had vaginal delivery within $24 \mathrm{hrs}$ from induction.

\section{Secondary outcomes}

Dosage of Prostaglandins Mode of delivery Hyperstimulation (defined as greater than five uterine contractions in 5minutes with fetal heart rate decelerations) Postpartum haemorrhage (defined as estimated blood loss greater than $500 \mathrm{ml}$ for vaginal delivery or greater than $1000 \mathrm{ml}$ for cesarean delivery), Chorioamnionitis and Neonatal outcomes.

In the PGE2 gel group, women received $0.5 \mathrm{mg}$ of Dinoprostone gel intracervically from the prefilled syringe, maximum of 3 doses, $6 \mathrm{hrs}$ apart after exposing the cervix by cuscos speculum and the patients were allowed to lie down for at least 30minutes. In the Oral misoprostol group, women received $50 \mathrm{mcg}$ oral misoprostol every 4 hours, upto maximum of 4 doses. Once the cervix becomes favourable (Bishops score $\geq 6$ ) or the patient enters into active labour, drug was discontinued. Further management of labour was with expectant management or amniotomy or augmentation of labour with intravenous oxytocin.

In the combination group, women received oral misoprostol 50mcg every 4 hours, maximum of 4 doses. In addition, a 20F Foleys bulb was inserted into the internal os by direct visualization with the aid of a sterile speculum and bulb was inflated with $50 \mathrm{ml}$ distilled water. Foleys catheter was pulled with gentle traction and was taped to patients medial aspect of the thigh. After Foleys bulb expelled, further management of labour carried on with amniotomy or intravenous oxytocin.

In all the three groups, patients who had unfavourable cervix $(\mathrm{BS}<6)$ even after completion of maximum doses, were started on intravenous oxytocin at 2milliunits/min increasing by 2 milliunits every 20 minutes until regular contractions occurs. In all the patients cardiotocography was used for fetal heart rate monitoring and uterine contractions assessed clinically. In our study, failed induction was labeled to patients whose bishop score was less than 6 even after $12 \mathrm{hrs}$ of intravenous oxytocin administration in the latent phase of labour.

The details of all the patients which included demographic characteristics, medical and antenatal history, course of labour, indication for labor induction and outcome were collected. The collected data were analyzed with IBM.SPSS statistics software 23.0version. To describe about the data descriptive statistics frequency analysis, percentage analysis were used for categorical variables and the mean and standard deviation were used for continuous variables. To find the significant difference in the multivariate analysis the one way ANOVA with Tukey's Post-Hoc test was used. To find the significance in categorical data, Chi-Square test was used. In both the above statistical tools the probability value, 0.05 is considered as significant level.

\section{Results}

A total of 201 women were enrolled in the study from March 2017 to August 2017[Fig 1]. Of these, 67 were assigned to PGE2 gel group, 69 assigned to oral misoprostol group and 65 to the combination group. A total of 6 women were excluded from the study ( 2 in PGE2 gel group, 3 in oral misoprostol group and 1 in combination group) due to deviation from protocol. This yielded 65 women in PGE2 gel group, 66 women in oral misoprostol group and 64 women in the combination group.

The three groups were comparable with regard to baseline characteristics including indication for induction of labour [Table 1]. Most of the women were at term, nulliparous. The most common indication for induction of labour was postdatism. The mean Bishop's score was similar in the three groups (3[range 1-6]).

The primary outcome were mean time interval from induction to active phase of labour was 9hours in the combination group, 16hours in PGE2 gel group and 18hours in the oral misoprostol group, which was statistically significant $(p<0.002)$ irrespective of parity in all the three groups. The mean time interval from induction to delivery was 16hours in the combination group, 21 hours in PGE2 gel group, whereas 25 hours in the oral misoprostol group. This was statistically significant $(\mathrm{p}<0.014)$ [Table 2] only in the nulliparous women.

The proportion of women who achieved vaginal delivery within $24 \mathrm{hrs}$ was $87 \%$ in the combination group, while it was $71 \%$ and $59 \%$ in the PGE2 gel group and oral misoprostol group, which was not statistically significant [Table 2]. When the three groups were stratified according to parity, the difference remained statistically significant in the nulliparous women than the parous women.

The mean number of doses of induction agents used in the combination group were lower compared to PGE2 group 
and oral misoprostol group [Table 3].There were no differences in oxytocin augmentation or epidural analgesia use. The incidence of secondary outcomes were not significantly different in three groups. [Table 4].

\section{Discussion}

In our study, we found that the combination group shortened the time interval from induction to delivery by $5 \mathrm{hrs}$ compared to PGE2 gel group and oral misoprostol group. No differences were observed in labour complications or adverse maternal and neonatal outcomes. There was no randomized controlled study comparing the efficacy of Foleys and oral misoprostol with PGE2 gel. "Recent study done by Gayathri mathuriya et al comparing Foleys with PGE2 gel concluded that induction with PGE2 gel has shorter time interval between induction and active phase of labour and also between induction and delivery. ${ }^{14,}$

A large systematic review and network meta analysis comparing the use of Foley's catheter, oral misoprostol and dinoprostone gel for cervical ripening in the induction of labour done by W Chen et al concluded that no method of labour demonstrated overall superiority. "Incidence of uterine hyperstimulation was low with Foleys catheter and caesarean section rates were lowest with oral misoprostol. 15" "Our findings were almost similar to the results of Samia Husain et al who had shorter induction to delivery time, more vaginal deliveries within $24 \mathrm{hrs}$ and need for less number of doses of induction agents with the combination group compared to oral misoprostol alone ${ }^{16,}$
"The major strength of this study is prospective randomized controlled study design, using three different induction agents, the PGE2 gel, the most easily available foleys bulb and incorporation of most acceptable route of administration of misoprostol. Mei-Dan et al showed that Foleys balloon is more cost effective than the double balloon catheter. ${ }^{17}$ ", We included both nulliparous and multiparous women making our results more generalizable.

"Patient acceptability and cost effectiveness are two major areas of concern while inducing labour. Another aspect is expectation from the method employed in terms of duration from induction to delivery. A few analysis evaluating a combined approach have been published. ${ }^{18,19 ",}$ Misoprostol is considered cheaper, safer and stored at room temperature. The oral route has additional benefit of patient acceptance. $^{20,}$ Foleys bulb is inexpensive and readily available in all situations, while PGE2 gel is cost expensive, needs refrigeration.

The total number of doses required for inducing delivery decreases when an additional method of induction is used, this leads to decreased incidence of complications (such as hyperstimulation and decreased Apgar at birth). In our study, the combination group needed only single dose in most cases and the difference was statistically significant.

"Limitations of our study were six participants dropped out of study due to deviation from protocol, small sample size Although we did not find any differences in mode of delivery, neonatal complications or labour complications, our study was sufficiently powered to assess the primary outcome".

Table 1: Demographic and Pregnancy Characteristics and indication of induction

\begin{tabular}{|l|c|c|c|}
\hline \multicolumn{1}{|c|}{ Characteristic } & $\begin{array}{c}\text { PGE2 group } \\
(\mathbf{n - 6 5 )}\end{array}$ & $\begin{array}{c}\text { Oral Misoprostol } \\
\text { group (n-66) }\end{array}$ & $\begin{array}{c}\text { Combination } \\
\text { group (n-64) }\end{array}$ \\
\hline Age & $28(20-40)$ & $28(20-40)$ & $29(20-40)$ \\
\hline Parity & $1(0-4)$ & $1(0-4)$ & $1(0-4)$ \\
\hline Body mass index & $28(26-29)$ & $28(26-30)$ & $27(26-29)$ \\
\hline Bishop Score & $3(1-6)$ & $3(1-6)$ & $3(1-6)$ \\
\hline Gestational age in weeks & $39(37-41)$ & $39(37-41)$ & $39(37-41)$ \\
\hline Indication for induction, n (\%) & & & \\
\hline Postdated & $22(33.8)$ & $27(40.9)$ & $25(39.1)$ \\
\hline Social reasons & $17(26.2)$ & $27(40.9)$ & $24(37.5)$ \\
\hline Decreased Fetal movements & $6(9.2)$ & $1(1.5)$ & $3(3.7)$ \\
\hline Gestational diabetes mellitus & $6(9.2)$ & $1(1.5)$ & $3(3.7)$ \\
\hline Pregnancy-induced hypertension & $6(9.2)$ & $2(3.0)$ & $4(6.3)$ \\
\hline Big baby & $7(10.8)$ & $1(1.5)$ & $2(3.1)$ \\
\hline Prolonged latent phase & $2(3.1)$ & $5(7.6)$ & $2(3.1)$ \\
\hline Bad Obstetric History & $1(1.5)$ & 0 & 0 \\
\hline Previous Intrauterine death & 0 & 0 & $1(1.5)$ \\
\hline Cholestasis & $1(1.5)$ & 0 & 0 \\
\hline
\end{tabular}

Data are expressed as mean (range) or n (\%) 
Table 2: Comparison of Primary outcomes stratified by Parity

\begin{tabular}{|c|c|c|c|c|}
\hline Parameters & $\begin{array}{c}\text { PGE2 } \\
\text { Group }(n-65)\end{array}$ & $\begin{array}{l}\text { Oral Misoprostol } \\
\text { Group (n-66) }\end{array}$ & $\begin{array}{l}\text { Combination } \\
\text { group (n-64) }\end{array}$ & P-Value+ \\
\hline \multicolumn{5}{|l|}{ Nulliparous } \\
\hline Time to enter into active phase (hrs), mean (range) & $16(12-19)$ & $18(13-23)$ & $9(7-11)$ & $0.002 *$ \\
\hline Induction to delivery time (hrs), mean (range) & $21(17-25)$ & $25(20-31)$ & 16(13-19) & $0.014^{*}$ \\
\hline Mode of delivery & & & & 0.492 \\
\hline Vaginal delivery & $42(82.4 \%)$ & $35(77.8 \%)$ & $31(72.1 \%)$ & \\
\hline Cesarean section & $9(17.6 \%)$ & $10(22.2 \%)$ & $12(27.9 \%)$ & \\
\hline Vaginal delivery less than $24 \mathrm{hrs}$ & $30(71.4 \%)$ & $21(58.8 \%)$ & $27(86.7 \%)$ & 0.048 \\
\hline \multicolumn{5}{|l|}{ Multiparous } \\
\hline Time to enter into active phase (hrs), mean (range) & $8(4-11)$ & $10(8-12)$ & $6(4-8)$ & $0.012^{*}$ \\
\hline Induction to delivery time (hrs), mean (range) & $9(6-13)$ & $13(11-15)$ & $10(8-13)$ & 0.067 \\
\hline Mode of delivery & & & & 0.428 \\
\hline Vaginal delivery & $14(100 \%)$ & $21(100 \%)$ & $20(95.2 \%)$ & \\
\hline Cesarean section & 0 & 0 & $1(4.8 \%)$ & \\
\hline Vaginal delivery less than $24 \mathrm{hrs}$ & $13(92.9 \%)$ & $21(100 \%)$ & $20(100 \%)$ & 0.225 \\
\hline
\end{tabular}

+One way Anova test or Chi square test, ${ }^{*} P$-value is significant at $<0.05$.

Table 3: Comparison of Secondary outcomes in three groups

\begin{tabular}{|l|c|c|c|c|}
\hline Parameters & $\begin{array}{c}\text { PGE2 group } \\
(\mathbf{n - 6 5})\end{array}$ & $\begin{array}{c}\text { Oral Misoprostol } \\
\text { Group (n-66) }\end{array}$ & $\begin{array}{c}\text { Combination } \\
\text { group (n-64) }\end{array}$ & P- Value+ \\
\hline No of doses, mean (range) & $3(1-3)$ & $4(1-4)$ & $1(1-4)$ & $0.000 *$ \\
\hline Oxytocin acceleration & $22(33.8 \%)$ & $17(25.8 \%)$ & $19(29.7 \%)$ & 0.599 \\
\hline Labour epidural & $12(18.5 \%)$ & $19(28.8 \%)$ & $16(25 \%)$ & 0.377 \\
\hline Fetal weight, mean (range) & $3(2.9-3.5)$ & $3(2.9-3.3)$ & $3(3.0-3.3)$ & 0.888 \\
\hline Indication for CS & & & 0 & 0.338 \\
\hline CPD & $1(11.1 \%)$ & 0 & 0 & \\
\hline Failed induction & 0 & $2(20 \%)$ & & \\
\hline Fetal distress & $4(44.4 \%)$ & $4(40 \%)$ & $5(38.5 \%)$ & \\
\hline Imminent Eclampsia & $1(11.1 \%)$ & $1(10 \%)$ & \multicolumn{2}{|c|}{0} \\
\hline Non progress of labour & $2(22.2 \%)$ & $2(20 \%)$ & $6(46.2 \%)$ & \\
\hline At request & $1(11.1 \%)$ & $1(10 \%)$ & $2(15.4 \%)$ & \\
\hline
\end{tabular}

+One way Anova or Chi square test, ${ }^{*} P$-value significant $<0.05$, CS-Cesarean section, CPD-Cephalopelvic disproportion

Table 4: Maternal and neonatal complications in three groups

\begin{tabular}{|l|c|c|c|}
\hline \multicolumn{1}{|c|}{ Parameters } & $\begin{array}{c}\text { PGE2 group } \\
(\mathbf{n - 6 5})\end{array}$ & $\begin{array}{c}\text { Oral Misoprostol } \\
\text { group (n-66) }\end{array}$ & $\begin{array}{c}\text { Combination } \\
\text { Group (n-64) }\end{array}$ \\
\hline Maternal Complications & & & $3(4.7 \%)$ \\
\hline Chorioamnionitis & $1(1.5 \%)$ & $2(3 \%)$ & - \\
\hline PPH & - & $2(3 \%)$ & $1(1.5 \%)$ \\
\hline Wound gaping & $1(1.5 \%)$ & $1(1.5 \%)$ & $1(1.6 \%)$ \\
\hline $\begin{array}{l}\text { rd degreePerineal tear } \\
\text { Neonatal Complications }\end{array}$ & $2(3.1 \%)$ & - & - \\
\hline 4 degreePerineal tear & $1(1.5 \%)$ & $1(1.5 \%)$ & \\
\hline & & & $6(9.4 \%)$ \\
\hline Tachysystole with Decelerations & $2(3.1 \%)$ & $9(13.6 \%)$ & $4(6.3 \%)$ \\
\hline Meconium stained liquor & $3(4.6 \%)$ & $4(6.1 \%)$ & - \\
\hline Shoulder Dystocia & $1(1.5 \%)$ & $1(1.5 \%)$ & - \\
\hline NICU admissions & $3(4.6 \%)$ & $2(3 \%)$ & - \\
\hline Neonatal death & - & - & $1(1.6 \%)$ \\
\hline Still birth & - & $1(1.5 \%)$ & - \\
\hline
\end{tabular}

Data are expressed as n(\%), PPH-Postpartum Haemorrhage, NICU-Neonatal intensive care unit 


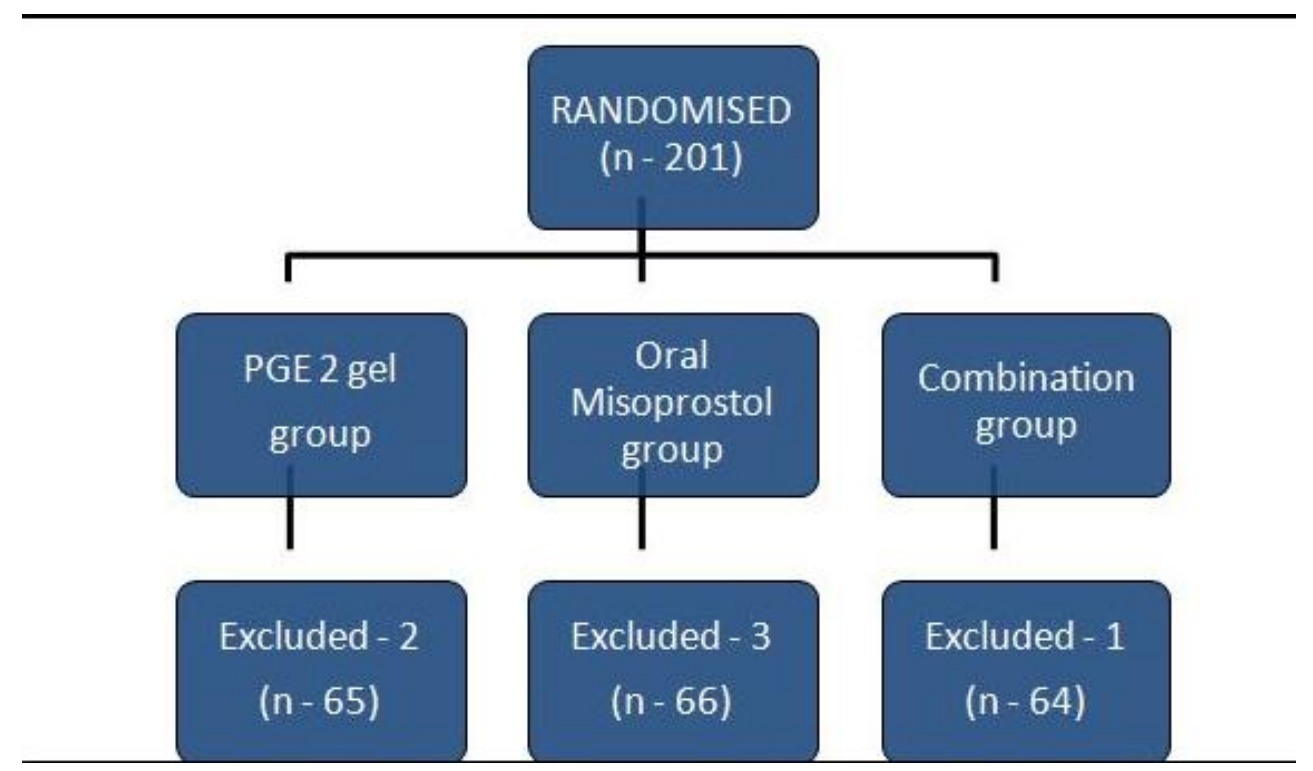

\section{Fig. 1: Profile of the study}

\section{Conclusion}

The results of our randomized trial showed that use of combination group resulted in shorter time interval from induction to delivery, compared with PGE2 group and oral misoprostol. These results suggest that combination of induction agents may be used to achieve safe and timely delivery in the presence of an unfavourable cervix. Although not directly evaluated in the study, decreased time interval from induction to delivery by 5hours would be significant for patients, health care providers and hospitals. Further studies should be of sufficient power to assess significant labour complications and adverse maternal and neonatal complications.

\section{Acknowledgments}

We thank our colleagues for their helpful advice during the course of this study.

\section{Conflict of interest: None.}

\section{References}

1. Joan Crane, St, John's NF, Line L, Gregory JR. Induction of labour at term. J Obstet Gynaecol 2001;23:717-28.

2. Alec S McEwan et al. Induction of labour: J Obstet Gynaecol Reprod Med 2008;18:1-6.

3. Vellekoop J, Vrouenraets FP, van der Steeg JW, Mol BW, Roumen FJ. Indications and results of labour induction in nulliparous women: An interview among obstetricians, residents and clinical midwives. Eur J Obstet Gynecol Reprod Biol 2009;146:156-9.

4. Nicole W, Karjane, Ellen L, Brock, Scott W, Walsh Induction of Labor Using a Foley Balloon, With and Without ExtraAmniotic Saline Infusion. Obstet Gynecol. 2006;107:234-239.

5. Ghanaei Mm, Sharami H, Asgari A. Labor induction in nulliparous women: a randomized controlled trial of foley catheter with extra-amniotic saline infusion. J Turkish-German Gynecol Assoc. 2009;10: 71-75.
6. Niromanesh S, Mosavi-Jarrahi A, Samkhaniani F. Intracervical Foley catheter balloon vs.pr ostaglandin in preinduction cervical ripening. Int J Gynecol Obstet 2003;81:23

7. Sorensen SS, Brocks V, Lenstrup C. Induction of labour and cervical ripening by intracervical prostaglandin E2. Obstet Gynecol 1985;65:110-14.

8. Ghanaei MM, Sharami H, Asgari A. Labour induction in nulliparous women: a randomized controlled trial of Foley catheter with extra amniotic saline infusion. J Turkish-German Gynecol Assocm 2009;10:71-75.

9. Niromanesh S, Mosavi-Jarrahi A, Samkhaniani F. Intracervical Foley catheter balloon vs. prostaglandin in preinduction cervical ripening. Int J Gynecol Obstet. 2003;81:23-7.

10. Jaya R, Rani S. Preinduction cervical ripening with endocervical PGE2 gel and placebo control study. J Obstet Gynecol India 1994;537-42

11. Alfirevic z, Aflaifel N, Weeks A. Oral misoprostol for induction of labour. Cochrane Database Syst Rev 2014;6:CD001338.

12. Alfirevic Z, Keeney E, Dowswell T. Labour induction with prostaglandins: a systematic review and network meta analysis. BMJ 2015;350:h217.

13. Ten EikelderML, Oude Rengerink K, Joswiak M. Induction of labour at term with oral misoprostol versus a Foleys catheter(PROBAAT-II): a multicente randomized controlled non-inferiority trial. Lancet 2016;387:1619 -28.

14. Gayatri Mathuriya, Sharad Pratap Singh Kushwaha, Shweta Pradhan. Comparative study of induction of labour with dinoprostone gel versus mechanical dilatation in unfavorable cervix. Int J Reprod Contracept Obstet Gynecol 2017;6(10):4363-6.

15. Chen W, Xue J, Preprah MK, Wen SW, Walker M, Gao Y et al. A systematic review and network meta-analysis comparing the use of Foley catheters, misoprostol, and dinoprostone for cervical ripening in the induction of labour. $B J O G$ 2016;123(3):346-54.

16. Samia Husain, Sonia Husain, Rubina Izhar. Oral misoprostol alone versus oral misoprostol and Foley's catheter for induction of labour:A randomized controlled trial. $J$ Obstet Gynaecol Res 2017;43(8):1270-77.

17. Mei-Dan E, Walfirch A, Valencia C, Hallak M. Making cervical ripening EASI:A prospective controlled comparison of single versus double balloon catheters. J Matern Fetal Neonatal Med 2014;27:1765-70. 
18. Sullivan CA, Benton LW, Roach H, Martin RW, Morrison JC. Combining medical and mechanical methods of cervical ripening. Does it increase the likelihood of successful induction of labour?. J Reprod Med 1996;41:823-8.

19. Hill JB, Thigpen BD, Bofill JA, Magann E, Moore LF, Martin $\mathrm{JN} \mathrm{Jr}$ et al. A randomized clinical trial comparing vaginal misoprostol versus cervical Foley plus oral misoprostol for cervical ripening and labour induction. Am J Perinatol 2009;26:33-8.
20. Abbassi RM, Sirichand P, Rizvi S. Safety and efficacy of oral versus vaginal misoprostol use for induction of labour at term. J Coll Physicians Surg Pak 2008;18:625-9.

How to cite this article: Balamurugan V, Joseph $\mathrm{K}$, Kurian R, Joseph T, Sivashannkari, Comparison of efficacy of PGE2 gel, Oral misoprostol and combination of foleys bulb with Oral misoprostol in predicting the Outcome of induction of labour: A randomized controlled trial. Indian $J$ Obstet Gynecol Res 2019;6(2):196-201. 